\title{
Dos visiones del hombre americano. d'Orbigny, Marcoy y la etnología sudamericana
}

Deux visions de l'homme américain. D'orbigny, Marcoy et l'ethnologie sudamérindienne

Two visions of the american man, d'Orbigny, Marcoy and the south-amerindian ethnology

Jean-Pierre Chaumeil

\section{(2) OpenEdition Journals}

\section{Edición electrónica}

URL: http://journals.openedition.org/bifea/6092

DOI: 10.4000/bifea.6092

ISSN: 2076-5827

Editor

Institut Français d'Études Andines

Edición impresa

Fecha de publicación: 1 diciembre 2003

Paginación: 459-465

ISSN: 0303-7495

Referencia electrónica

Jean-Pierre Chaumeil, « Dos visiones del hombre americano. d'Orbigny, Marcoy y la etnología sudamericana », Bulletin de l'Institut français d'études andines [En línea], 32 (3) | 2003, Publicado el 08 diciembre 2003, consultado el 01 diciembre 2020. URL : http://journals.openedition.org/bifea/6092 DOI : https://doi.org/10.4000/bifea.6092

\section{c)}

Les contenus du Bulletin de l'Institut français d'études andines sont mis à disposition selon les termes de la licence Creative Commons Attribution - Pas d'Utilisation Commerciale - Pas de Modification 4.0 International. 


\title{
DOS VISIONES DEL HOMBRE AMERICANO. D'ORBIGNY, MARCOY Y LA ETNOLOGÍA SUDAMERICANA*
}

\author{
Jean-Pierre CHAUMEIL **
}

\section{Resumen}

La reciente publicación de los viajes por América del Sur de d'Orbigny y Marcoy invita a comparar, tanto del punto de vista científico como por su recepción frente al gran público, sus contribuciones respectivas al estudio de las sociedades indígenas de las tierras bajas. Si bien los dos viajeros se oponen en muchos aspectos, compartieron sin embargo actitudes comunes frente a las poblaciones observadas, como también sufrieron un cierto descrédito por parte de los medios académicos de aquel entonces. Sea por falta o exceso de "rigor científico", la trayectoria de ambos viajeros revela a su vez mucho sobre la construcción del "americanismo" a mediados del siglo XIX.

Palabras claves: Americanismo, viajes, siglo XIX, culturas indígenas, clasificaciones, eurocentrismo.

\section{DEUX VISIONS DE L'HOMME AMÉRICAIN. D'ORBIGNY, MARCOY ET L'ETHNOLOGIE SUDAMÉRINDIENNE}

\section{Résumé}

La publication récente des voyages en Amérique du Sud de d'Orbigny et de Marcoy invite à comparer, tant du point de vue scientifique que pour leur réception auprès du grand public, leurs apports respectifs à la connaissance des sociétés indigènes des basses terres. Si les deux voyageurs s'opposent en effet sur de nombreux aspects, ils n'en adoptèrent pas moins des attitudes communes face aux populations observées. Tout deux souffrirent de surcroît un certain discrédit de la part du milieu académique de l'époque. Que ce soit par excès ou manque de « rigueur scientifique », la trajectoire des deux voyageurs est instructive sur la façon dont s'est constitué l'" américanisme » au milieu du XFXiècle.

Mots clés : Américanisme, voyages, XIX ${ }^{e}$ siècle, cultures indigènes, classifications, eurocentrisme.

* Debido a un error hemos tenido que volver a imprimir el texto completo de este artículo después de la salida del número 32(3) de 2003. El presente texto es, entonces, el único válido.

** EREA-CNRS: BP $n^{\circ}$ 8, 94801, Villejuif, Cedex. France. E-mail: jeanpierre.chaumeil@vjf.cnrs.fr 


\title{
TWO VISIONS OF THE AMERICAN MAN. D'ORBIGNY, MARCOY AND THE SOUTH-AMERINDIAN ETHNOLOGY
}

\begin{abstract}
The recent publication of the travels in South America of d'Orbigny and Marcoy leads us to compare - from a scientific point of view as for their reception to the general public - their respective contributions to the knowledge of lowland amerindians. If the two travellers contrast on numerous aspects, they have however adopted common attitudes toward the indigenous populations. They have moreover (but for diverse reasons) known some kind of discredit from academic circle. However that may be, the trajectories of the two travellers is very instructive to inderstand the way in which the "americanist community" conform in the middle of the nineteenth-century.
\end{abstract}

Key words: Americanism, Travels, Nineteenth-century, Indigenous Cultures, Classifications, Eurocentrism.

La publicación y reedición, con poco intervalo, de las obras de Alcide d'Orbigny (2002) y de Paul Marcoy (2001), invitan a reflexionar sobre el valor y la originalidad de sus aportes respectivos a la ciencia etnológica con referencia al estudio de las poblaciones indígenas de América del Sur.

Si bien los dos viajeros se diferencian en muchos aspectos (viajero oficial mandado por el Museo nacional de Historia natural, d'Orbigny se benefició de la mejor formación académica por aquel entonces y de todo el apoyo institucional necesario, mientras que Marcoy, viajero independiente, autodidacta, mezcla de aventurero y artista, carecía totalmente de tal formación y apoyo), ambos desempeñaron sin embargo sensibilidades y actitudes algo similares frente a las poblaciones con las cuales compartieron un instante el modo de vida, así como denunciaron con la misma firmeza la aceleración del deterioro ambiental producido por la cada vez mayor explotación indiscriminada de los recursos naturales. Ambos dieron también mucha importancia al papel de la iconografía como parte integrante de sus trabajos y se animaron en varias empresas de divulgación científica (d'Orbigny en el Voyage pittoresque publicado bajo su dirección y en el cual imaginó el itinerario de un viajero; Marcoy a través de la revista muy popular por aquella época, Le Tour du monde). Los dos sufrieron además críticas o indiferencia, hasta descrédito, por parte de ciertos medios científicos, d'Orbigny por su fidelidad a Cuvier y al fijismo (controversia con Darwin) (Chaumeil, 2002), Marcoy por su "infidelidad" a la Academia así como por el tono juzgado demasiado novelesco de sus escritos (controversia con Raimondi) (Chaumeil, 2001). Sea por exceso o falta de "rigor científico", la trayectoria personal de ambos viajeros revela a su vez mucho sobre el proceso de construcción de una comunidad científica americanista naciente.

Las diferencias académicas y de estilo, así como las semejanzas, entre ambos viajeros nos parecen por otro lado interesantes para establecer una comparación en la medida que ofrecen dos extremos, por así decirlo, de lo que produjo en materia de viaje etnográfico la primera mitad del siglo XIX. Vale recordar sin embargo que Marcoy emprendió sus viajes 15 años después de d'Orbigny (regresó de su viaje al Amazonas 
cuando d'Orbigny acababa la publicación de los últimos volúmenes de su Viaje), en una región intermedia (Andes centrales y Amazonas) entre las zonas exploradas por este último (parte meridional de América del Sur) y por Humboldt (parte septentrional). Si se puede establecer ciertos paralelos, como lo hizo Rivet (1933), entre Humboldt y d'Orbigny, o incluso Castelnau, uno tendría en cambio dificultad en ubicar una filiación precisa con la obra mucho más impresionista de Marcoy.

Sea lo que sea, si de manera típica d'Orbigny y Marcoy ilustran dos maneras distintas de viajar y de aproximarse a la realidad sudamericana, sus apreciaciones de las sociedades indígenas no eran del todo diferentes. El valor de ambos testimonios en este campo no consiste quizás tanto en la precisión etnográfica (aunque este aspecto tiene importancia), menos todavía en las especulaciones teóricas sobre el hombre americano (de las cuales no queda gran cosa hoy día), sino más bien en una cierta percepción y un interés por la organización de las sociedades indígenas que era algo nuevo por aquel entonces, prefigurando de algún modo los inicios de la etnología moderna (de la observación de la naturaleza hacia el análisis de las sociedades observadas). Pensamos que ahí radicó uno de sus mayores aportes por la influencia que tuvo sobre las transformaciones progresivas en la manera de ver y acercarse a los grupos indígenas, rompiendo de cierta manera con las ideas simplistas y despectivas que dominaban por aquella época la mayoría de los círculos científicos. Esto no quiere decir que no compartían esta visión europeocéntrica del mundo tan característica de la época y a la cual podían difícilmente escapar (la necesidad de "civilizar" y la idea de "progreso"), sino que defendían al mismo tiempo las culturas indígenas como formando sistemas complejos y dignos de ser estudiado como tal. Este cambio progresivo de mirada, que se inició por cierto con Humboldt, repercutió también en su visión de la naturaleza como medio frágil que se debía proteger. Es muy significativa la "modernidad" de ambos viajeros sobre este tema que se ha vuelto central hoy en día, como bien se sabe, en los discursos y políticas del llamado "desarrollo sustentable"; podríamos al respecto citar párrafos enteros escritos por ambos viajeros que podrían ser aprobados como modelo en el género por cualquier medioambientalista actual.

Para nutrir la comparación entre ambos americanistas, vale considerar tres tipos de aportes: etnográfico, lingüístico e iconográfico.

Es indiscutible que d'Orbigny ha sido en su época uno de los que mejor ha descrito y estudiado las poblaciones indígenas de las regiones meridionales de América del Sur (sus predecesores, Félix de Azara y Tadeo Haenke no libraron quizás la misma cantidad y cualidad de datos). Fue también uno de los primeros sabios en haber emprendido el estudio de un vasto grupo humano considerando simultáneamente los caracteres físicos, las civilizaciones y las lenguas.

Para evaluar su aporte, es necesario distinguir estos dos momentos o etapas en su reflexión antropológica, entre el tiempo de la descripción (el Viaje) y el de la síntesis (El Hombre americano).

En el Viaje, d'Orbigny ofrece una relación bastante completa así como una suma de datos muy a menudo inéditos (pero que deben mucho, por cierto, a informaciones o manuscritos de misioneros conseguidos en las aldeas misionales, procedimiento que, dicho de paso, era común a la mayoría de los viajeros en aquel entonces, incluyendo a 
Marcoy) sobre la historia, la geografía, la economía y la etnología de las sociedades encontradas.

Es sobre todo en Bolivia, donde residió más tiempo y con las mejores condiciones, que d'Orbigny hizo las observaciones más detalladas sobre los grupos indígenas, los guarayos, mojos, chiquitos y sobretodo yuracares, mencionando incluso por primera vez a grupos como los siriono. La riqueza y la precisión de los datos recogidos (superando en varios casos los proporcionados posteriormente por Lardner Gibbon o por Erland Nordenskiöld) hacen de esta parte del Viaje el elemento fuerte de su obra del punto de vista etnográfico. Muchos de estos documentos son únicos y constituyen todavía para numerosos etnólogos las únicas fuentes disponibles y fidedignas sobre estas remotas comarcas. Así lo confirmó Vincent Hertzel (comunicación personal) a propósito de los yuracares sobre los cuales está redactando su tesis. No solamente los datos proporcionados por d'Orbigny (que incorporan también informaciones que le dio el misionero la Cueva) permiten llenar importantes lagunas etnográficas (sobre mitología, duelos de flecha, discursos de salutación o ritos de pubertad), sino que permiten tener una visión mucho más amplia de este grupo. D’Orbigny ofrece por otro lado buenas descripciones de las ceremonias sincréticas indígenas en las misiones, que son de interés tanto para el historiador como para el etnólogo.

Uno de los otros aportes notables de d'Orbigny a la antropología es el de haber puesto fin a uno de los mitos sudamericanos más tenaz desde el siglo XVI (desde el relato de Pigafetta): el de los "patagones gigantes". Demostró de manera definitiva, a partir de datos antropométricos recogidos por él, la falsedad de tal aserto viejo de tres siglos.

Muchas otras observaciones son valiosas, otras contradecían las certezas de la época, pero recibieron confirmación desde entonces, como por ejemplo las relaciones juzgadas como infundadas que estableció d'Orbigny entre quechua y aymara, cuando

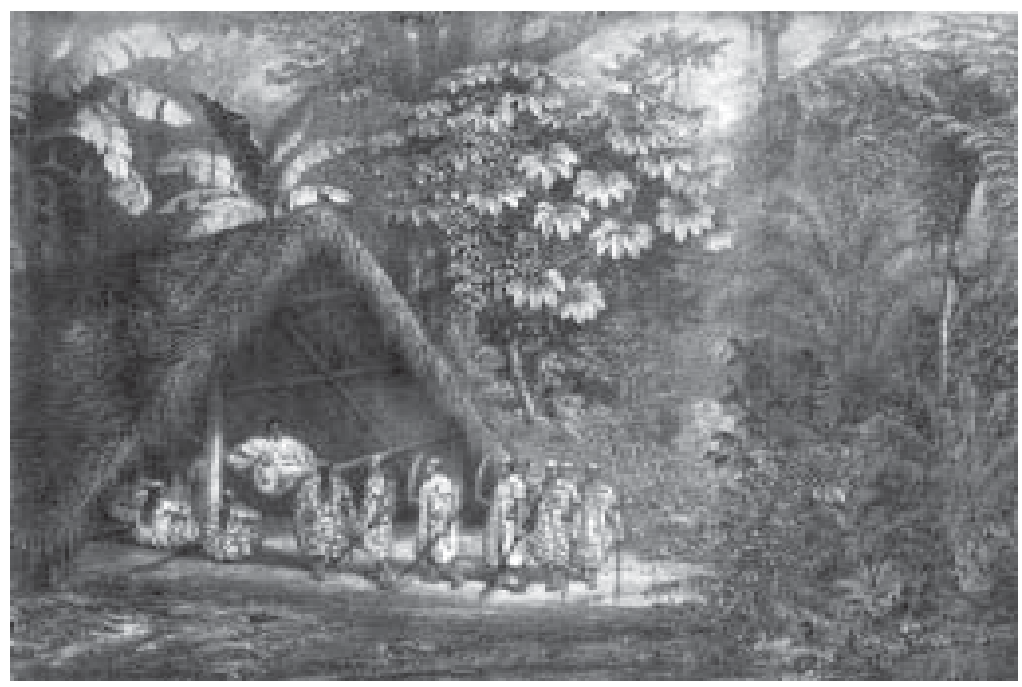

Fig. 1 - Visita a los yuracarés (sacado de d'Orbigny, 2002: 1320). 
las investigaciones recientes insisten sobre las múltiples imbricaciones (históricas, culturales, lingüísticas) entre ambos conjuntos (Cerron Palomino, 2000).

Su contribución en el campo lingüístico no ha sido menos importante, en particular por la notación de los primeros vocabularios de lenguas indígenas hasta entonces desconocidas, y Paul Rivet (véase sus numerosos trabajos sobre lingüística boliviana) mostró el inmenso partido que pudo sacar de los materiales lingüísticos inéditos de d'Orbigny así como de los vocabularios que trajo de las misiones. Su preocupación por las lenguas nativas entraba de hecho como factor clave en su proyecto de clasificación del hombre americano, pero al mismo tiempo ayudó a resolver problemas de identificación lingüística y sobretodo reveló la situacion de multilingüismo de muchos grupos que podían expresarse en 4 ó 5 idiomas distintos, cuestionando así los presupuestos (que perduran a veces hasta hoy) sobre el carácter cerrado, repliegado y de poca abertura sobre el exterior de los grupos indígenas. Pero al mismo tiempo no pudo librarse de un cierto eurocentrismo cuando declaró que el mantenimiento de estas lenguas, saludadas en otro capítulo por su gran riqueza expresiva, representaba al final el principal obstáculo frente a la "marcha progresiva de la civilizacion".

Por otro lado, las magníficas láminas de vistas y costumbres (cerca de 500) que ilustran el Atlas del Viaje, y que muchos autores elogiaron en su tiempo, son documentos iconográficos del más alto interés etnográfico. Se sabe que numerosos viajeros de la época utilizaron la iconografía como una forma de mise en scène dramática de sus aventuras vividas. Nada de eso con d'Orbigny (a diferencia de Marcoy) que se sirvió del dibujo ante todo como fuente documental. Tenemos aquí una mina todavía poca estudiada cuyo valor etnográfico perdura intacto.

No se puede decir lo mismo de su ensayo intitulado El Hombre americano que ha sido sin embargo considerado como su obra maestra. Se trataba de la primera tentativa de sistematización científica aplicada a escala del subcontinente (amputado no obstante de la parte propiamente amazónica) en la cual d'Orbigny proponía una nueva clasificación de los pueblos sudamericanos en tres grandes "razas", subdivididas en

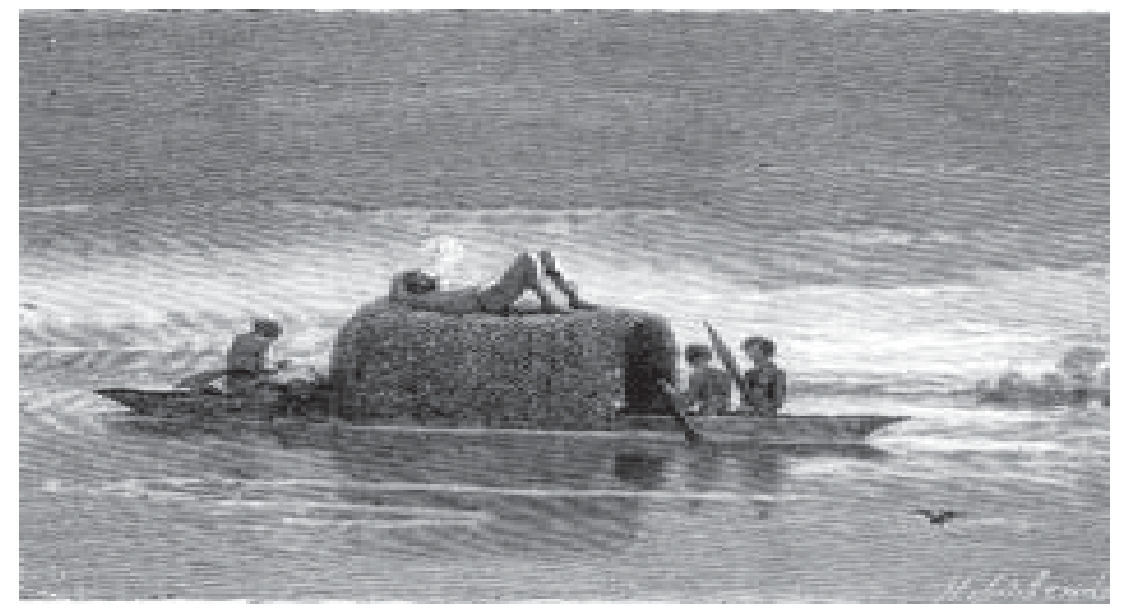

Fig. 2 - Ensoñación al crepúsculo (sacado de Marcoy, 2001: 482). 
"ramales" y "naciones". Tuvo gran éxito y se quedó largo tiempo como referencia obligada. Pero como pasó con muchas de las grandes síntesis, su sistema de clasificación como su visión del hombre americano, si guardan valor para la historia de las ideas, están en gran parte superados hoy en día. Los antropólogos actuales no se refieren más a tales tipologías para determinar las características de las poblaciones humanas, de mismo modo que los etnólogos sudamericanistas previlegian los sistemas de interacciones entre grupos o conjuntos regionales para definir los colectivos indígenas mucho más allá, vale decir, de los criterios de tipo físico o lingüístico. Si esta parte de la obra de d'Orbigny perdió todo valor de referencia, la mayoría de sus observaciones y descripciones, sus dibujos y levantamientos cartográficos no solamente quedan muy valiosos sobre regiones y sociedades todavía mal conocidas, sino que representan en varios casos testimonios únicos.

La obra de Paul Marcoy, de la cual hablaremos a continuación, se distingue, como se dijo, de la de d'Orbigny en varios aspectos, empezando por su carácter poco oficial y académico. A diferencia de su predecesor, Marcoy (de su verdadero nombre Laurent Saint Cricq) era una mezcla de aventurero y artista en delicadeza con el mundo académico (que odiaba tanto como al clero) pero que tenía, como d'Orbigny, un sentido agudo de la observación y de las relaciones humanas. Viajó por su cuenta muy temprano en América del Sur y nos dejó una obra original y pintoresca, de mucha sensibilidad etnográfica a pesar de su tono novelesco que, agregado a polémicas, imprecisiones biográficas y efectos literarios, le valió un cierto descrédito en los medios académicos de aquel entonces. Sostuvo por ejemplo haber realizado su travesía del subcontinente siguiendo el Amazonas sobre una apuesta hecha en un puerto de la costa del Pacífico con un capitán de navio escocés quien sostenía, de su lado, que la ruta oceánica por el Cabo de Hornos era más rápida para alcanzar la desembocadura del Amazonas, que cruzando por tierra. Huelga decir que Marcoy perdió su apuesta (si es que realmemte fue así, lo que se puede dudar) pero sí logró cruzar el subcontinente, compartiendo incluso una parte del viaje con la famosa expedición encabezada por Castelnau, con el cual como bien se puede imaginar terminó peleándose (Chaumeil, 2001).

En su obra principal, publicada en dos lujosos tomos y de mucho éxito, Marcoy demostró plenamente sus talentos como narrador y etnógrafo. Pero, como en el caso de d'Orbigny, es necesario distinguir en su obra dos momentos o dos etapas de su reflexión entre, por un lado, sus observaciones botánicas, geográficas y etnográficas, y por otro sus tentativas e hipótesis sobre el origen del hombre americano. En verdad, el tono alegre y picante de las primeras se vuelve medio ácido y aburrido cuande se trata de disertar sobre la cuestión de los orígenes.

A diferencia de d'Orbigny que era un monogenista convencido, Marcoy adoptó hasta cierto punto las tesis poligenistas y llegó a clasificar la población indígena de América en dos tipos primordiales ("americano-mongol" e "irano-aria") con los cuales pensaba poder explicar las diferencias que observó entre las civilizaciones andinas y amazónicas. Vale decir que su clasificación se demarcaba radicalmente de la establecida por d'Orbigny, obra que conocía y contra la cual reaccionó, pero la tipología que propuso no era mejor y fue rápidamente invalidada. En este campo, Marcoy no hizo obra muy relevante, conformándose con poco sentido crítico a las especulaciones de su época, o simplemente reaccionando contra los supuestos "errores" de Humboldt, d'Orbigny, Castelnau, Markham o Raimondi. 
Su contribución real a la etnografía viene, como en el caso de d'Orbigny, de su relación directa con las poblaciones indígenas, pero con un toque especial y algo inimitable (que le valió muchas críticas) debido a su manera muy singular de mirar, de sentir, de percibir y de narrar. Es seguramente sobre el estilo narrativo que Marcoy se distancia más de d'Orbigny. Nos proporcionó sin embargo un amplio panorama etnográfico que sigue sirviendo de referencia a los estudios posteriores sobre estas regiones (en particular sobre las sociedades del Ucayali). Puzo en evidencia muchos de los mecanismos de la dinámica social indígena (los sistemas de movilidad socioespacial y de guerra, los circuitos de intercambio a larga distancia, etc.) sobre los cuales las investigaciones actuales se apoyan para especificar ciertas formas, todavía activas, de organizaciones regionales y multiétnicas. Insistió también, al igual que d'Orbigny, sobre el impacto de las misiones en los modos de vida y de reagrupamiento indígenas (el descriptivo de la misión de Sarayacu constituye una mina para una etnografía de las misiones). Ambos vieron en este proceso tanto la marca del progreso como el inicio de la decadencia de las culturas indígenas, posición paradójica que reflejaba las contradicciones de la época (entre exotismo romántico y ciencia), cuando precisamente el discurso de la ciencia se hizo progresivamente instrumento del progreso.

Aunque muchos de los datos etnográficos de Marcoy son relevantes y hasta novedosos para la época, algunos necesitan sin embargo ser revisados, como por ejemplo los apuntes demográficos que son muy subestimados o ciertas identificaciones étnicas equivocadas, lo que se puede fácilmente entender vista la confusión que reinaba en las clasificaciones por aquel entonces (recordamos que d'Orbigny no consideró los grupos del Amazonas en su clasificación).

En el campo lingüístico también hizo algunos aportes (pero en menor escala que d'Orbigny), notando varios vocabularios indígenas que se utilizan principalmente hoy como base comparativa (es evidente que ambos viajeros no hablaban las lenguas indígenas, con excepción del quechua y guaraní de las cuales tenían nociones).

En materia de iconografía, tanto Marcoy como d'Orbigny eran extraordinarios dibujantes y recurrieron mucho a la ilustración en sus obras respectivas, pero lo hicieron de manera muy distinta según sus objetivos, dependiendo también eso del soporte editorial escogido y del público destinatario. D’Orbigny, como naturalista, pensó la iconografía basicamente en términos de fuente documental (atlas), mientras que Marcoy, como artista, la penso mucho más como parte integrante del texto, o mejor dicho como un "texto global", a la manera de una escritura "mixta" (textual y gráfica), así como bien lo mostró Régine Bénize-Daoulas (2001; 2002). La revista Le Tour du monde en la cual publicó la primera edición de su viaje ofrecía esta posibilidad de combinar texto e imagen con el fin explícito de suscitar la curiosidad y la imaginación del lector. No es por sorprendernos que se volvió el periódico de aventura el más popular de la época. Muchos viajeros publicaron allí y conocieron tanto éxito que se les ofreció luego editar sus relatos en libro, lo que ocurrió con Marcoy. Se puede suponer al respecto que la presencia del autor, que aparece en muchos de los grabados vestido de sus ineluctables sombrero y poncho, hacía parte del efecto escénico destinado a dar una mayor credibilidad a su relato y propiciar al mismo tiempo la complicidad del lector (Bénize-Daoulas, 2001; 2002). 
Si encontramos por cierto en esta fabulosa iconografía mucho de la imaginación de Marcoy, así como muchos de los fantasmas occidentales sobre tan lejanas tierras, no carece sin embargo de valor etnográfico como lo hemos podido comprobar a propósito de los grabados referentes a los yagua. Pero sería todavía más importante encontrar algún día los croquis y acuarelas originales del autor: solo así se podría tener una idea más exacta de su sensibilidad etnográfica a través del dibujo.

A modo de conclusión, vemos que a pesar de las distancias que separan los dos viajeros que no tenían al principio mucho del etnólogo, con formaciones, sensibilidades y motivaciones académicas diferentes, ambos aportaron, a su manera, mucho al americanismo y a la ciencia etnológica. No lo hicieron tanto a través de sus teorías sino por la precisión de sus observaciones así como, y quizás sobre todo, por los cambios que suscitaron en la manera de percibir el mundo indígena tratando, con los medios de los cuales disponían, de hacer valer el punto de vista de los indígenas, lo que era lejos de constituir la norma en los medios científicos de aquel entonces. Haciendo eso, hicieron realmente obra de etnólogo.

\section{Referencias citadas}

BENIZE-DAOULAS, R., 2001 - L’Amérique du Sud selon Paul Marcoy (1853-1876) : contribution à l'écriture d'un exotisme latino-américain en France. Thèse de Doctorat, Université Paris III, 623p.; 2 tomos.

BENIZE-DAOULAS, R., 2002 - Voyage en Paulie-Laurencie, essai sur une construction narrative polyphonique. Bulletin de l'Institut Français d'Études Andines 31(2): 183-218.

CERRÓN-PALOMINO, R., 2000 - El Aimara como lengua oficial de los incas. Conferencia en el Centro G-H. Haudricourt/Celia, Villejuif.

CHAUMEIL, J.-P., 2001 - Un viajero sin prisa a mediados del siglo XIX, Laurent Saint-Cricq (Paul Marcoy). In: Paul Marcoy. Viaje a través de América del Sur, Del Océano Pacífico al océano Atlantico: 15-45; Lima: Instituto Francés de Estudios Andinos/Pontificia Universidad Católica del Perú/Banco Central de Reserva del Perú/Centro Amazónico de Antropología y Aplicación Práctica.

CHAUMEIL, J.-P., 2002 - Quand le naturaliste se fait ethnologue... In: Alcide d'Orbigny. Du Nouveau Monde... au passé du monde (P. Taquet, ed.): 64-69; París: Nathan et Muséum national d'Histoire naturelle.

MARCOY, P., 2001 [1869] -Viaje a través de América del Sur, del océano Pacífico al océano Atlántico, 567p. + 632p.; Lima: Instituto Francés de Estudios Andinos/Pontificia Universidad Católica del Perú/Banco Central de Reserva del Perú/Centro Amazónico de Antropología y Aplicación Práctica. 2 tomos.

ORBIGNY, A. d', 1839 - L'homme américain (de l'Amérique méridionale), considéré sous ses rapports physiologiques et moraux, 423p. + 372p.; París: Chez F-G. Levrault. 2 tomos.

ORBIGNY, A. d', 2002 [1945] -Viaje a la América Meridional, 1785p.; La Paz: Instituto Francés de Estudios Andinos/Plural editores. 4 tomos.

ORBIGNY, A. d' (publié sous la direction de), 1836 - Voyage pittoresque dans les deux Amériques, 568p.; París: chez L. Tenré, Libraire-éditeur.

RIVET, P., 1933 - D'Orbigny, ethnologue In: Commémoration du voyage d'Alcide d'Orbigny en Amérique du Sud, 1826-1833: 15-26; París: Masson \& Cie, publications du Muséum national d'Histoire naturelle $n^{\circ} 3$. 